\title{
CONSIDERATIONS ON THE USE OF EXPLOSIVE SUBSTANCES FOR THE DESTRUCTION OF METALLIC STRUCTURES
}

\author{
Florin ILIE \\ ilieflorinv@yahoo.com \\ Mircea VLADU \\ vladumircea57@yahoo.com \\ Gabriela MIHĂILǍ-LICĂ \\ mihailag2001@yahoo.com \\ Bogdan-Mihai GEORGESCU \\ bogdan.502.xt@gmail.com \\ “NICOLAE BĂLCESCU” LAND FORCES ACADEMY, SIBIU, ROMANIA
}

\begin{abstract}
Incidents with IEDs containing metallic elements in the vicinity of the explosive substance pose a high degree of risk, endangering safety, peace and public order. In such situations, the methods and procedures applied as response by the authorities are cumbersome and risky, given the improvised nature of these incidents. In this paper we intend to analyze the destructive effect of explosive substances on certain metallic materials and we focus on a U-shaped metallic structure.
\end{abstract}

KEYWORDS:

Trotyl, metallic structure, destruction, shock wave

\section{Conceptual delimitations}

Lately, one has noticed the exacerbation of the use of terror as a means of achieving and imposing the interests of certain states, groups or organizations in the context of the amplification of the conflicting states in different geographic areas of the globe and the perpetuation and amplification of states generated by lack of trust between certain states or ethnic groups due to nationalistic or religious criteria.

It is hard to believe and there are very few those who predict a decline in this extremist-terrorist phenomenon, a theory fueled especially due to the fact that the main generating causes are not diminished (the multitude of political, ethnic, religious, national, territorial, social or economic issues).

A statistical analysis of the terrorist acts and incidents shows that in more than half of the cases, improvised explosive devices with an explosive charge in metallic envelope or containing metallic materials were used in order to amplify the destructive effect.

The aspects to be considered by the pyrotechnic specialists when acting on an explosive device, especially when it contains 
metallic materials in its structure, depend, to a large extent, on the anticipation of the parameters and on the knowledge of the effects of its detonation.

The identification of the critical, dangerous and safe areas implies, among other things, establishing the dependence between the characteristics and, in particular, the amount of explosive substance and the presence of metallic materials in its vicinity. Unfortunately, it is often difficult to predict or to know the parameters of an explosive device and it is very difficult to apply a general model for calculating the destructive effects of explosives on metal structures.

\section{Theoretical considerations}

In the presence of a shock wave generated by an explosive charge, the metallic materials react differently than in the case of an ordinary stress. Knowing and understanding this type of scientific behavior in the strain of metallic structures under the action of explosive substances depends largely on the appreciation of the possibility to apply, for the extreme conditions of the shock, the data obtained by the usual tests, to which the terms dependent on the characteristics of the shock wave impacting the metallic material are added.

Some parameters such as the state of initial stress in the material, the composition and the geometry of the metallic structure in the vicinity of the explosive substance, the maximum shock pressure, the duration of the shock action, the strain velocity can greatly influence the mechanical properties of the materials, such as the flow limit or, in general, the shape of the stress-strain diagram. Often, depending on the type of shock and its characteristics (mainly influenced by the amount of explosive), the metallic material is destroyed (Năstăsescu, 2002).

Under the conditions of applying an external load, the metallic materials react either in an elastic or in a plastic manner. In the first case the material is considered to be a continuous and homogeneous medium, a hypothesis on the basis of which stressstrain relations can be deduced, in conjunction with the determination of constants expressing the relationship between stresses and strains for the studied material (Bârsan, 2002). In the $2^{\text {nd }}$ case, it is considered that besides the change of the initial shape, the resistance of the material can be reduced depending on certain factors (strain velocity, temperature and composition).

In general, establishing the mechanical properties of the metallic materials is doneby means of the stress-strain graph, based on the data obtained from conventional stretch tests. The mechanical properties of the statically stressedmaterials are the following:

- the elasticity limit,

- the proportionality limit,

- the flow limit (the conventional flow limit).

By continuing to apply the load, after a certain period of time, the resistance limit of the material will be reached, which is the stress that the material can withstand without being destroyed. This is represented by the maximum ordinate of the stress-strain curve. Following the stretch tests to which the metallic materials are subjected, information is obtained, which can be graphically represented in the form of a real stress curve - real strain. Thevalues of the actual stress are calculateddepending on the load and on the actual surface subjected to the load.

Starting from the ratio stress-the respective relative strain and considering the assumption that the stress value does not exceed the elastic limit, one can establish several elastic moduli or elasticity constants, the most used being the following:

- the longitudinal elasticity modulus (Young) E,

- the transverse elasticity modulus G,

- the volumic elasticity modulus $\mathrm{K}$ (Rotariu, 2008).

In principle, the factors that influence the properties of the materials are the 
externallyapplied pressure, the strain velocity, the initial temperature, and other factors (microstructure, etc.).

When external loads are applied by shock, the influence of the pressure on the mechanical properties is quite big, resulting in a change in the tension-strain curve. The influences of the high pressure tension on the mechanical properties of the materials are as follows:

- increased resistance to stretching and compression;

- linear increase of the longitudinal and transverse modulus of elasticity with the maximum shock pressure.
The study of the influence of the strain velocity on the properties of the metallic materials is made by using special techniques with high velocities for applying the load, either of stretching or compression, resulting in some significant details in the case of the increase of the strainvelocity:

- increase of the material flow limits;

- increase of the resistance limits of the materials (Figure no. 1) (Năstăsescu, 2002).

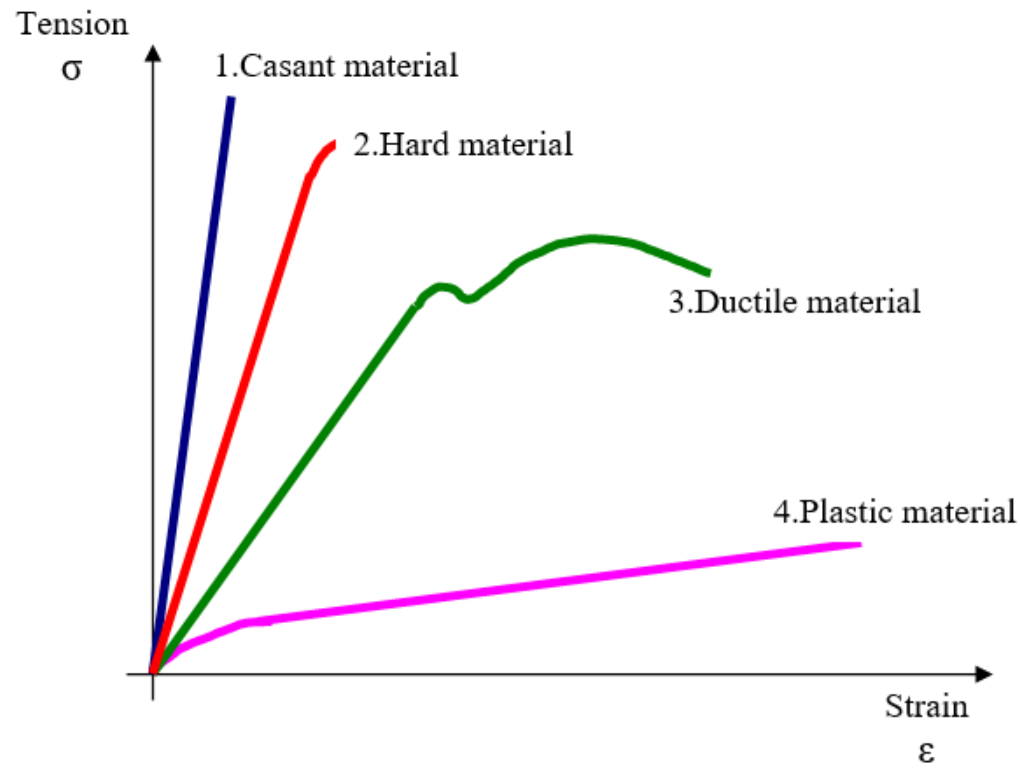

Figure no. 1. The characteristic forms of the stress-strain curves (Source: Năstăsescu, 2002)

The properties of the metals are affected by the temperature by the modification of the structure of the metal and by modification of the limits of the action of the various types of possible strains.

At high temperatures there appears the phenomenon of the flow of the metals, and in the case of low temperatures, the destruction due to fragility is the predominant cause of the decrease in resistance (Huh, Kang \& Han, 2002).
3. The experimental testing of the effect of the explosive substances in the destruction of metallic structures

In order to perform the tests we used an electrical ignition system composed of an electrical cap, conductive cables and the electric power source (the burster), as well as trotyl blocks (cartridges) with the following characteristics:

- weight -75 and 100 grams;

- cylindrical shape (Figure no. 2). 


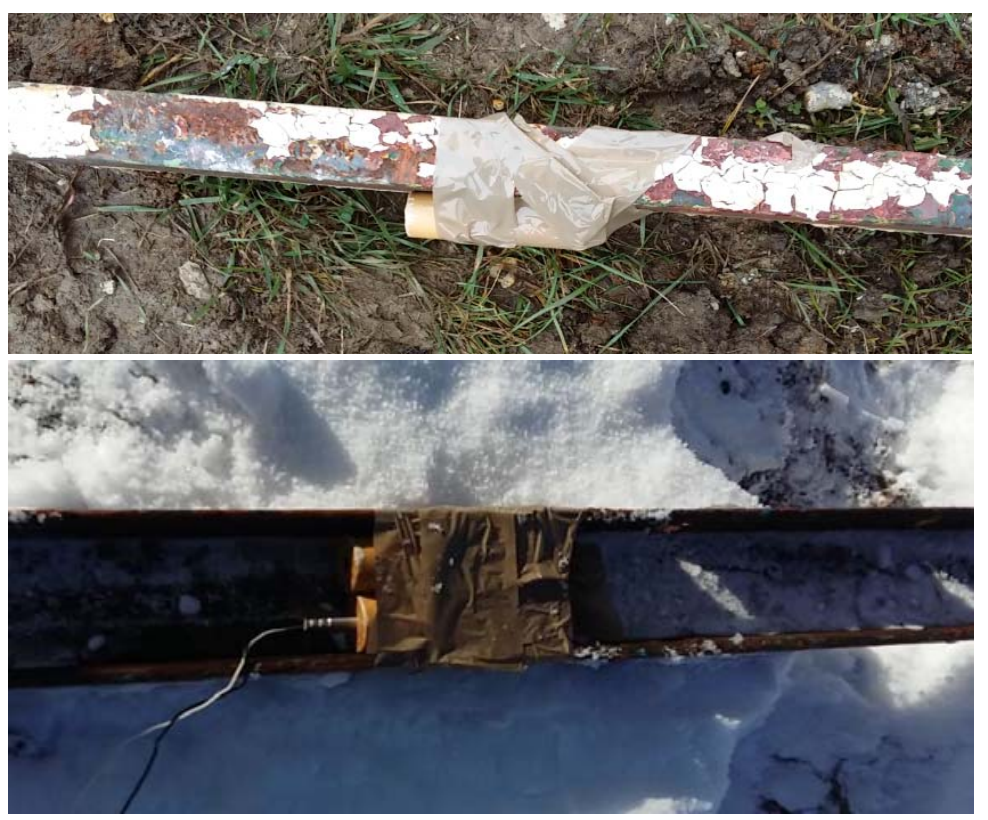

Figure no. 2. The system before detonation

(Source: own processing)

The trotyl (2, 4, 6 trinitrotoluene) is solid, crystallized in rhombohedral system; it is colorless; the residue of the impurities gives it a yellow color and it melts at $80.8^{\circ} \mathrm{C}$; it has a real density of $1,654 \mathrm{~g} / \mathrm{cm}^{3}$. The light does not decompose it, but only darkens it simultaneously with the insignificant increase in sensitivity. The trotyl is resistant to temperature. When heated to $150{ }^{\circ} \mathrm{C}$, it does not decompose even after 40 hours, it does not react with the usual metals, and humidity does not influence its stability (Orban \& Goga, 1997).

The metallic structures (Figure no. 3) on which we performed the tests are with a
U profile (UNP100, UNP120, UNP140 and UNP 160 variants), made of steel (steel quality: S 235, S 275, S 355 according to EN 10025 - 2) and they can be used for various steelwork items, with applications in both civil and industrial fields. The hotrolled U-profile is made of carbon steel and has applications in the field of constructions and equipment. It is usually used for architectural structures. It can be welded or joined by different processes, and dimensions are presented in Table no. 1 (UNP Profile, 2019).

Table no. 1

Dimensions of metallic structures with U profiles

\begin{tabular}{|c|c|c|c|c|c|c|c|}
\hline $\begin{array}{c}\text { Profile } \\
\text { name and } \\
\text { size }\end{array}$ & $\begin{array}{c}\text { Density per } \\
\text { linear } \\
\text { meter }\end{array}$ & $\mathbf{h}_{\mathbf{1}}$ & $\mathbf{b}$ & $\mathbf{s}$ & $\mathbf{t}$ & $\mathbf{h}_{\mathbf{2}}$ & Section \\
\cline { 2 - 8 } & {$[\mathbf{k g} / \mathbf{m}]$} & {$[\mathbf{m m}]$} & {$[\mathbf{m m}]$} & {$[\mathbf{m m}]$} & {$[\mathbf{m m}]$} & {$[\mathbf{m m}]$} & {$\left[\mathbf{c m}^{\mathbf{2}}\right]$} \\
\hline UNP 100 & 10.90 & 100 & 50 & 6.0 & 8.5 & 64 & 13.50 \\
\hline UNP 120 & 13.70 & 120 & 55 & 7.0 & 9.0 & 82 & 17.00 \\
\hline UNP 140 & 16.40 & 140 & 60 & 7.0 & 10.0 & 98 & 20.40 \\
\hline UNP 160 & 19.30 & 160 & 65 & 7.5 & 10.5 & 115 & 24.00 \\
\hline
\end{tabular}



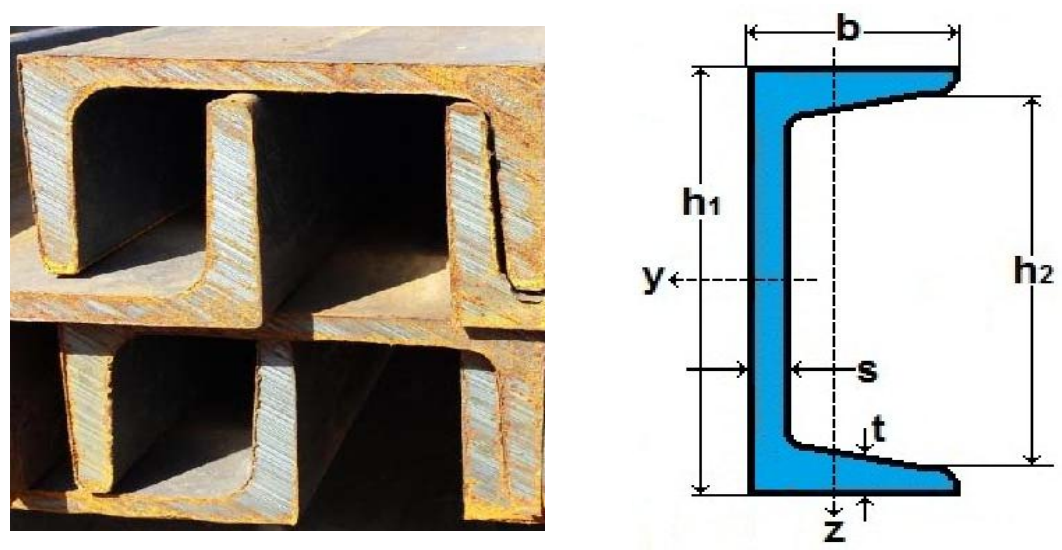

Figure no. 3. Metallic structures with U profile

(Source: Profile UNP, 2019)

\section{Results and discussions}

Shock waves can be generated by three methods:

- by using detonating explosives placed in direct contact with the metallic materials;

- by the impact of a projectile on a metallic structure,

- by using high power lasers (Orban \& Goga, 1997).

Our paper aims to analyze the destructive effect of the trotyl on some U-shaped metallic structures.

Generating a shock wave in the inert environment by detonating the explosives, placed in contact with the metallic structure, can be considered a particular case of transmitting a shock wave from one environment to another.

The charges were placed in direct contact with the metallic structure. In accordance with the specifications in the specialized literature, we placed the explosive charges on a cross section of the structure, aiming both at a destruction effect and at a shearing effect. In this sense we used the "couple" display of the explosive charges, that is to say, the explosive blocks that act from opposite directions being offset from each other.

The calculation of the charges was done by turning the U-shaped working profile into simple geometric shapes, and the total value that was obtained was multiplied by 2 and then it was weighted to multiples of the mass of the explosive blocks.

For each simple geometric structure, the required mass of explosive substance was established by using the formula:

$$
m_{i}^{T N T}=S_{i} \cdot 20
$$

In which $S_{i}$ represents the surface of the cross-section of the geometric structure obtained from the unfolding of the working profile (Vladu \& Ilie, 2018).

In addition to the main research direction regarding the use of the trotyl for the destruction of metallic structures, other secondary directions were also pursued:

- the observation of the phenomenon of the explosion;

- the propagation of the shock waves through the surrounding environment;

- the visualization of the manner in which shock waves evolve and their composition.

A number of 2 tests were performed for each U profile separately, and the results were in accordance with the performed calculations and simulations, i.e. each metal structure (U profile) was destroyed (Figure no. 4). We should mention the fact that due to the construction of the U-profile with the opening upwards, we could easily make the system necessary for the fixing of the concentrated charges (Vladu \& Ilie, 2018). 

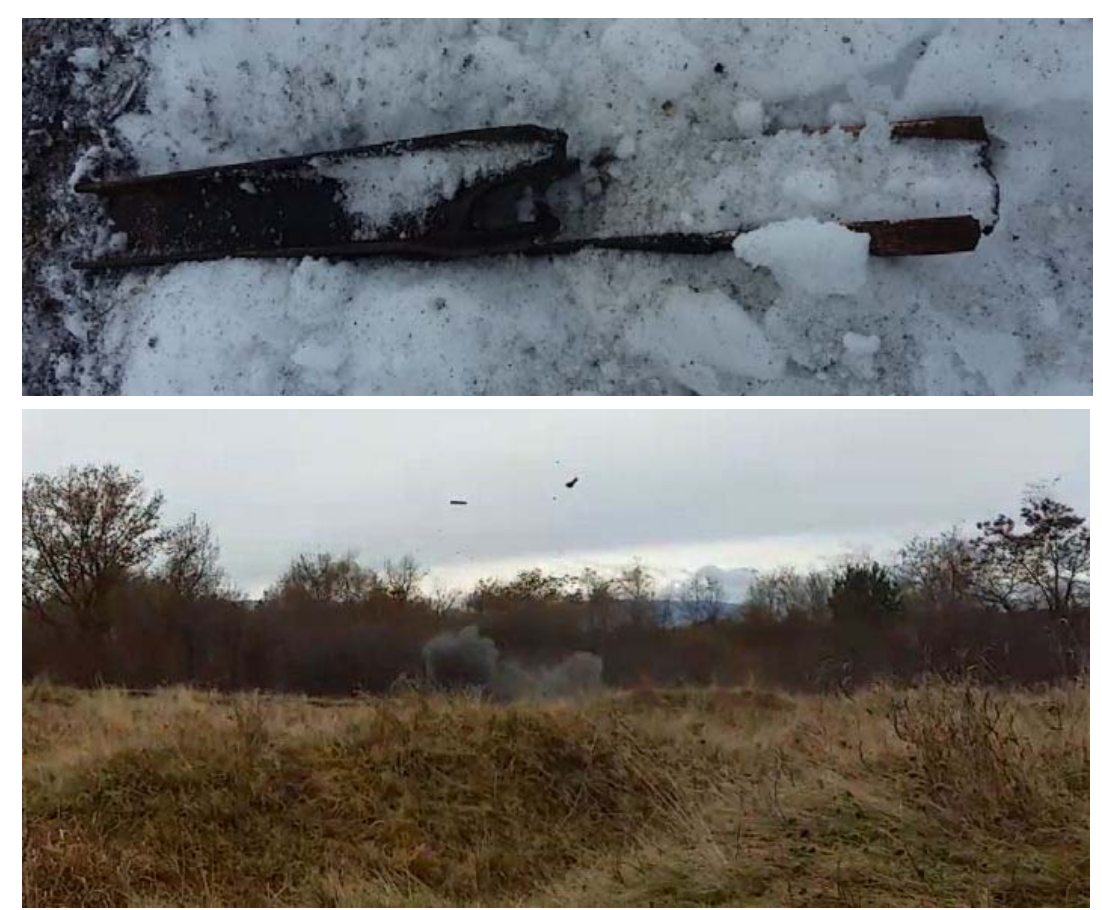

Figure no. 4. System after detonation

(Source: own processing)

\section{REFERENCES}

Bârsan, G. (2002). Teoria elasticităţii. Bucureşti: Editura M.P.M. Edit Consult, ISBN 973-99634-1-2.

Huh, H., Kang, W. J., \& Han, S. S. (2002). A Tension Split Hopkinson Pressure Bar for investigating the dynamic behavior of sheet metals. Experimental mechanics, Vol. 42, nr. 1, 8-17.

Năstăsescu, V. (2002). Rezistenţa Materialelor - Solicitări Simple. Bucureşti: Editura Academiei Tehnice Militare.

Orban, O., \& Goga, D. (1997). Fabricaţia şi proprietăţile substanţelor explosive. Bucureşti: Editura Academiei Tehnice Militare.

Profil UNP. (2019). available at: https://www.h-metal.ro/ro/profil-unp/101, accessed on 12 September 2019.

Rotariu, A.-N. (2008). Comportamentul materialelor la viteze mari de deformare. Modelare şi testare. București: Editura Univers Știinţific.

Vladu, M., \& Ilie, F. (2018). Distrugeri în diferite medii. Sibiu: Editura Academiei Forțelor Terestre "Nicolae Bălcescu". 